\title{
Fashion Marketing and the Role of Fashion Store Atmosphere in Effective Sales Growth
}

\author{
Prof. Dr.oec. Sarmite Jegere \\ University of Latvia \\ Riga, Latvia
}

\begin{abstract}
Aim of the study - Explore the nature of fashion marketing and its role in creation of the store's atmosphere and effective product sales growth. In terms of the study in 2016 was carried out a survey of part-time students. 384 respondents were interviewed. Aim of the survey was to determine consumer preferences related to store atmosphere in Latvia. The responses are summarized in the following nine categories: comfort; the number of visitors and their nature; identified personnel; kind and friendly sellers; large trading hall; a positive presentation/design; sales equipment and stands; recommendations for the selection of products from the seller; minimalism. Given the fact that the social factor is decisive, service providers (sellers) must have deep knowledge of the implementation of existing products and be able to give each customer the appropriate consultation. Recognize the type of customer and successfully communicate. All this requires proper training.
\end{abstract}

Keywords: fashion, fashion marketing, store atmosphere

\section{Introduction}

Fashion has been aggressive mannered for many decades by dictating their rules, thereby interfering with the consumer, but nowadays it has become much more attentive to their users. Manufacturers and designers must take into account what today's educated society want, as it has become much more attentive and understands perfectly what is good and what is not. Emotional marketing is a vivid tool of fashion marketing led by intuition and is based on consumer experiences; the clients need the reminder as well as the formation of emotions and needs. It is necessary to understand the psychological, social and cultural needs of the society when working in the fashion sector, because fashion marketing is based on many psychological, social science terms, and this knowledge must be linked to intuition and feelings - to be able to hear their customers, to be able to reach their customers and retain their long-term communication. Fashion Marketing therefore has become a communication channel through which it is possible to realize the supply and identify the demand. On the other hand the fashion industry is so innovative and dynamic, that there cannot be applied any standardized and codified marketing methods. Aim of the study - Explore the nature of fashion marketing and its role in creation of the store's atmosphere and effective product sales growth.

\section{Materials and Methods}

In Latvian language there is no identical translation of the semantic etymon Fashion Marketing. Using synonyms it can be translated as "fashion commercialization", "Preparation of market for fashion products", "fashion market comparison". This paper uses a simple translation - fashion marketing.

Breward (2003) describes fashion as an essential tool to express the characteristics of social, political ideas and aesthetic taste. Perrna (1987) believes the fashion is the expression of era. Such a broad interpretation of this concept corresponds to today's consumer society where, in most cases, life style reflects the social status and success (mobile phones, watches, cars, clubs, clothing, accessories, etc.). This expanded concept of fashion is pointed out by Polhemus and Procter (1978), who observed that a given term is used as a synonym to - style, jewelry and clothing.

Fashion essentially includes changes determined by a series of short-term trends or fads. From this point of view fashion can exist in every human activity, ranging from medical care to popular music. Many believe that the textile industry, sewing and footwear products are elements of the fashion industry. Besides clothes and shoes for fashion items are considered furniture coating (finish), clothes, curtains, and wall and floor coverings. 
If we list the fashion magazines, it is noticeable that the fashion extends to food, buildings, music, cars, perfumes and cosmetics. Traditionally, fashion changes every season, but new trendy spots or mini-collections return on a monthly basis. Precarious nature of fashion is not something new. In early 20th century P. Poiret has said that "clothing making is the industry, which is based on novelty" (Leymarie, 1987, 21). Novelty makes the fact that fashion is not long term. Reich (2004) defined the difference between fashion and style, saying that fashion has no style, since it is always just a fashion.

Barnard (2002) believes that clothing is the most common way to express and to focus attention on the fashion in the media. For example, it talks about the need of people to be in a society and at the same time be an individual and those trendy clothes is a way to meet this challenging set of expectations and requirements. To make the changes the fashion industry has to constantly create new products.

Fashion is formed only in the mind of the mass associated with expressions such as trendy or fashion this season. G. C. Chanel said: "Fashion won't be real until it will come out on the streets. Fashion, which does not go out from the salon is just as insignificant as a fancy dress ball" (Charles-Roux, 2004, 11)." Fashion cannot be changed by showing 25 dark blue suits on the catwalk, " - Anna Wintour, chief editor of Vogue magazine (Foley, 2004, 16). Creativity and design is the most important components of fashion. Product creation is a result of very frequent changes, which are the essence of fashion, as well as its relation to creativity and continuous improvement or transformation of design skills. These products are basic, expected and improved from a marketing perspective.

Creativity of the design gives a part of mechanism to personnel which respond to the need for changes in this industry. At the same time, abilities and skills to identify the products that customers need and what they will buy, is very important to the industry as well. Marketing can help provide the additional knowledge and skills necessary to ensure that the creative component is used to form the greater competitive advantage and achieve business success and growth (see table No 1).

Fashion marketing is an application of different types of technology and business philosophy, which is concentrated on customers or potential customers of clothing and related products and services - in order to gain long-term results in the company. Fashion marketing is different from all other marketing spheres. Nature of fashion i.e. the characteristic changes, gives different accents to classical marketing activities. In addition, the role of design in both the management and buyer's demand reflection makes up several fashion marketing approaches. Fashion marketing in practice connects to the fact that the fashion industry is huge both in size and business structure options, to serve and ensure customer needs. From small business, which goes from self-employed knitwear designers to major multinational co-operatives to fashion brand factories. Diversity remains a major effect. The fashion industry has grown internationally during the changes in EU legislation and the elimination of customs barriers, as well as changes in Eastern Europe. This means considerable variations in culture, social and economic prospects of its participants. The result of this size, experience and perspective variations is that the fashion marketing practice is not uniform on a national level and is independent on the international level.

The key issue of debate on the topic of fashion marketing is the tension between the views by designers and marketing specialists:

- young fashion designers have to gain at least formal knowledge in business or marketing, but the designers do not learn them in Latvia;

- similarly, the formal marketing training can help staff to understand the role of design in business;

- students of design have traditionally been taught to solve problems as if there is no "pressure, or price", so that creativity flourish, free from structural factors (i.e. they do not notice them);

- spontaneity, eclecticism and willingness to take risks challenging the status quo are some of the values that are the heart of traditional design education;

- Marketing training in the contrast includes a variety of values. Professionals are taught to be systematic and to analyze the upcoming challenges. Success will be if you carefully research and plan, rather than be spontaneous or ignore market realities, such as competitor prices;

- marketing personnel often do not understand the artistic dimension of the design or the quality of product development in many aspects due to imperfection of training;

- smart designers and marketing professionals understand the need to upgrade the professional skills, understand the need for communication, as well as differences in visual and production stages and is absolutely one 
minded on evaluation of functional aspect of clothing i.e., particular seasons clothing should be waterproof or washable in washing machines.

To sum up: designers see marketing specialist as the persons who suppress their freedom and fantasy, but marketing specialists think that designers are undisciplined and careless or superficial concerning the profit and prices.

This view is a stereotype that is formed in different education systems, as well as misunderstanding the perspective of two specialists - designers and marketers. So there are still two opposing views of fashion marketing:

1. Marketing, which is centered on design: fashion marketing as a promotion;

- as such, is used as a synonym for promotion;

- designers have real power, but marketing experts help sell their ideas to the public;

- in practice this means that all marketing activities focuses on public relations or commercial activities (in agencies);

- the main segment - wealthy individuals who need a creative style - film directors, musicians, actors, etc. This is the way famous fashion designers created their own business (Madonna's corset).

2. Marketing, which focuses on marketing: design is the reason for study:

- marketing dominates and as a results of marketing research the designer is responsible for the fulfillment of customer expectations;

- retail representatives may affect the design of planned production, requiring some changes for bargaining price (pricing).

As a result, fashion marketing concept is a completely different form of cooperation between the designers and marketing professionals. If the designer understands how marketing personnel is able to understand that in fashion industry design can create and respond to customer demand and expectations - progress is ensured.

Marketing, that's applied to fashion industry, has to assess the role of design as detailed style and nuances specifications. This cooperation is supported by the fact that many of the fashion award winners have been successful not only in the field of design, but also in sales and profits. Therefore, fashion marketing concept is not only a theoretical model, it works in practice as well (see table No 2).

Main tasks of fashion marketing specialists are:

1. Fashion marketing research;

2. Implementation of fashion product management.

Design manager takes care of how to deliver a large quantity of a variety of shirt to retailer. Shirts must be complied with other garments such as jackets, vests, ties. All of these can be supplied from different manufacturers. Design Manager has to gather information and deliver it to the designers so that they would have an adequate summary. Then the manager will sell these designs in a presentation to retailers, usually in fierce competition. Design manager's knowledge of retail customers and awareness of the company's costs provides effective marketing.

3. Fashion promotion.

The manager shall submit information to the person who will prepare brochures visual and textual materials. Summary must contain numbers - how much prospects and addresses, as well as the most important fashion marketing objectives for this event.

4. Fashion product division. For example, explore possible opportunities in the case of expansion:

- Opportunity to own a business franchise;

- Selection of largest stores and submission to the rules;

- Cooperation with the leading women's clothing designers to build in addition collection each season. Necessary: marketing research, analysis of the business status and future marketing strategy preparation.

\section{Fashion product positioning and pricing.}

For example, a retailer discovers that a competitor sells imported silk underwear with the same design and quality, but the price is $20 \%$ lower. Marketing decision should be based on the positioning and price evaluation, taking 
into account, the company's strategic objectives, as well as customers' sensitivity to prices. The Fashion Marketing process can be seen in figure No 1.

Fashion marketing specialist tasks are not limited with this. Sphere, that is poorly studied in Latvian, but which can play a crucial role in the selection of goods is a fashion store atmosphere. Retail stores that aim to work in long term are bound to consider customer needs and improve store design, creating a pleasant atmosphere - one that a customer wants to stay and make their purchases. Store design is an essential element of fashion marketing strategies, establishing competitive advantage. Evaluating the costs for the purchase of clothing and individual preferences, buyers reduce the time spent in the store. Marketing professionals have a duty to delay a buyer in the store as long as possible. For this to happen it is not enough simply to have shelves full of goods, they must create the atmosphere that makes the shopping process easy, pleasant and joyful. If buyers will consider shopping a boring way of spending their free time, they will spend it in other ways. Trade space uniqueness can become a crucial point in buyer's decision to attend one or the other store.

A false belief that the product value and price are the same still exists among vendors. The value is a set of emotional experiences that occur as advantages of the buying process. Advantages of the store are design, equipment, customer service, conveniences and product quality. In turn the price is not equivalent to the value, but only one of its parts (Berry, 1996).

Researches show that companies who find it difficult to maintain a competitive advantage based on price policy, promotion and business location, atmosphere of the trade area provides an opportunity to deviate from its competitors (Kenhove, 1997). Buyers spend more time in the shop with a pleasant atmosphere and also spend more money. Atmosphere works relaxing on visitors. But it can also cause discomfort and enrage. It should be remembered that customers buy more and spend money in a positive rather than negative-store atmosphere. Store atmosphere's role is further reinforced by the fact that $70-80 \%$ of purchasing decisions are taken in the store, getting acquainted with the product.

Given that customer expectations may change, the trader must be aware of consumer expectations including store atmosphere. What is customer satisfaction? It is the result when your expectations match with activities in the store. Inadequacy promotes frustration, conformity guarantees satisfaction. F. Kotler (1973) was the first who mentioned the concept of atmosphere in retail. Marketing experts emphasize that the decisive elements of atmosphere is the music, light, and social factors. (Bellizzi, 1983; Baker, 1992). Some authors point sensory information as primary. It is associated with cognitive or emotional state of the purchaser, which could affect behavior and product perception (Gardner, 1985). On the other hand, Baker (Baker, 1992) summarized previous studies and extracted three categories of factors that helps evaluate the overall atmosphere of the store:

-Environmental Factor;

-Design Factor;

-Social Factor.

Store environmental factors associates with atmospheric background characteristics that affect the buyer in subconscious level are: temperature, light, music and fragrances. Acting background - soothing music, soft light in contrast of bright light, helps to build more cheerful mood. Too loud music leaves negative effects, which annoys customers. Too bright light dazzles the buyer's and their ability to see the goods and causes discomfort, similar to unpleasant odors. Store design is much more prominent compared to environmental factors. It has aesthetic and / or functional nature. The functional elements of the store are design, comfort, private atmosphere, and aesthetic - architecture, materials, colors and product placement. Functional nature of planning is due to the fact that it helps to navigate while shopping and cause satisfaction to clients. It is known that a broad passage is more positive than the narrow and crowded one. Location can ensure the better purchase - the fitting rooms and equipment. Trade equipment not only provides sale, but also perform an aesthetic function (even the floor). The design is a key element because:

-it is more visible and measurable;

-useful for both store employees and customers.

Social factor affect people in the store directly - number of sellers and buyers, types of behavior. Often, just the seller's behavior greatly influences the buyers and their satisfaction. With increasing awareness of consumer, they initially trust the seller, waiting for a deeper knowledge and his readiness to respond to their needs. Buyers want not just a seller but seller - consultant. Seller's appearance and behavior has also a positive impact on customers. 
Social factor affects also the number of visitors in the store. If there are more people than seller can manage and he cannot pay any attention to them, in many cases the buyers just delay non-emergency purchases.

Behavior of other consumer's has an impact to shopping as well. Stores, which are loved by "undisciplined" buyers, are not popular and full of "positive" customers.

Large number of people in the market hall is an obstacle in effective shopping. There is tension in the crowd and confusion, but the smallest number of people in the store is less constrained and provides positive emotions satisfaction and peace. However Latvian buyers feel some discomfort when they are the only ones in the store. Retail store atmosphere with carefully thought design gives the consumer a positive and efficient consumer experience, which makes it enjoyable. The biggest problem facing retailers - to combine fashion and lifestyle, as well as determine the necessary atmosphere of the store which must be effective and at the same time procure pleasure.

In Hong Kong (2004) there was conducted a study of store atmosphere and consumer decision in store selection. $90 \%$ supported the statement of the essential role of store atmosphere and brought the factors listed in the following order: a social factor, design, and environment.

In the structure of Environmental factor respondents noted the essential element of atmospheric formation:

1.purity of the trade hall;

2.lights, music, aroma, temperature, noise; Respondents suggested the significant design elements:

1.store size;

2.Dressing room and its size.

Largest number of the respondents considered service as the most important element in the social factor. Number of people in the store was also a prominent element (Hines, Bruce, 2007).

\section{Results}

Empirical study in 2016 was the survey of part-time students in 9 branches of the University of Latvia that are located in Aluksne, Cesis, Madona, Bauska, Jekabpils, Kuldiga, Tukums, Ventspils and Liepaja. Survey was conducted among 384 respondents. The survey aimed to establish consumer preferences related to store atmosphere in Latvia. The responses are summarized in the following 9 groups.

1. Convenience: it refers to fitting cabins and the existence of the chair in it, aisle width, and the exact placement of goods, noise, temperature, and store cleanliness.

2. The number of visitors and their nature: the number of buyers their type and their description, store personnel competence and their number, and the hope that both the seller and buyers will not be rude and insensitive i.e. describes their behavior.

3. Identifiable staff: provides that employees have the same uniform or at least the same style and colors, as well as clips with their names. Meeting and escorting consumers are not particularly important in Latvia, but everyone recognizes the importance of recognition and respect from the seller when greeting or escorting.

4. Welcoming and friendly sellers: showing qualities such as responsiveness, sensitivity, kindness.

5. Extensive trade hall: recognizes the size of a store with a lot of resting areas, signs of large-scale, modern shop windows.

6. Positive Presentation: means light, music, pleasant scents.

7. Commercial equipment and stands: product location attracts most of the buyers, the respondents noted that they like the stands made from timber.

8. Seller Recommendations on the selection of products.

9. Minimalism: supporting a light background and light buildings.

Empirical part of the study was an in-depth discussion with one of the groups of respondents on their expressed wishes; as a result it became clear that social factors are most important to Latvian consumers. On the final question, will a positive atmosphere in the store form a positive, satisfied experience of the customer, the overwhelming majority answered "yes" and only a few respondents considered it to be insignificant (especially when they are very hungry or have limited funds). 


\section{Conclusions}

Our results show that the store's atmosphere is often a key customer selection, and superior to other factors, such as - the store layout, product range and price. Shops with warm and friendly staff, customers associated with a high sense of satisfaction when visiting them. This allows concluding that service is a key element of the social dimension. In this respect, fully consistent with the theoretical results of the research: practically all respondents gave this factor an important role in building positive emotions during shopping. The fact that two other factors (environmental and design) did not gain as much support as a social factor that does not mean that they can be ignored. Only their impact on the positive sense of shopping is slightly lower.

Given that the social factor is decisive to service providers - sellers must have deep knowledge of existing products in sale and be able to provide appropriate consultation to each customer. Recognize the customer type and communicate successfully. All this requires proper training to be undertaken by the few schools in Latvia that educate sellers.

Table No 1 Two points of view on fashion marketing

\begin{tabular}{|c|c|c|}
\hline Notice example & $\begin{array}{c}\text { Fashion marketing is the same } \\
\text { as the promotion of }\end{array}$ & $\begin{array}{c}\text { The design must be based solely on } \\
\text { marketing research }\end{array}$ \\
\hline Assumption & Sell what we make & Make what we sell \\
\hline Orientation & Centered on the design & Centered on the marketing \\
\hline $\begin{array}{c}\text { Reference to any } \\
\text { deficiencies }\end{array}$ & $\begin{array}{c}\text { The high failure rate } \\
\text { Depends on the intuition }\end{array}$ & $\begin{array}{c}\text { Gentle design, } \\
\text { stifled creativity }\end{array}$ \\
\hline
\end{tabular}

Table No 2 Fashion marketing concept

\begin{tabular}{|l|c|c|c|}
\hline $\begin{array}{l}\text { Caring for fashion } \\
\text { design }\end{array}$ & High & $\begin{array}{c}\text { CENTER ON } \\
\text { THE DESIGN }\end{array}$ & $\begin{array}{c}\text { FASHION MARKETING } \\
\text { CONCEPT }\end{array}$ \\
\cline { 2 - 4 } & Low & FAILURE & CENTER ON MARKETING \\
\hline & \multicolumn{3}{|c|}{ Low } \\
\hline
\end{tabular}

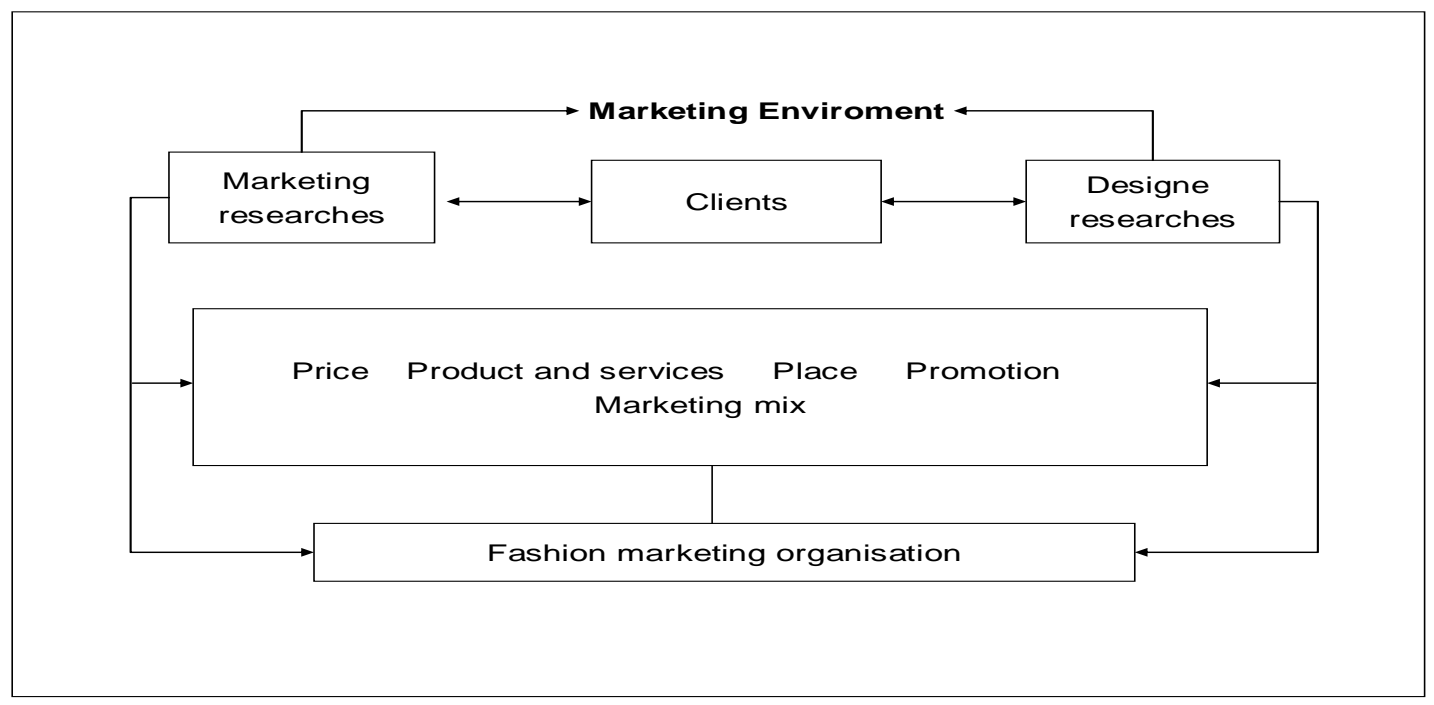

Figure No 1 Fashion marketing process

\section{References}

Baker J.( 1992) An experimental approach to making retail store environmental decisions. Journal of Retailing, 68, 471-495 p.

Barnard M. (2002) Fashion as communication. London, 372 p. 
Bellizzi J.A.(1983) The effects of color in store design. Journal of Retailing, 59, 21-45 p.

Breward C. (2003) Fashion. Oxford University press, 398 p.

Berry L.L.(1996) Retailers with a future: the new value equation. Chain Store Age, October, 4-6 p.

Charles-Roux E. (2004) The World of Coco Chanel, Friends Fashion Fame, London, 179 p.

Foley B. ( 2004) Marc Jacobs. Assouline Publicity NY, 246 p.

Gardner M.P. (1985) Towards a methodology for assessing effects of in-store atmosphere, Chicago, 27-31 p.

Hines T., Bruce M.(2007) Fashion marketing, Oxford UK, 409 p.

Kenhove P.V. (1997) The relationship between emotional states and approach or avoidance responses in a retail environment. The International Review of Retail, Distribution and Consumer Research , 7 (4), 351-368 p.

Kotler P.(1973) Atmospherics as a marketing tool. Journal of Retailing, 49, 48-64 p.

Leymarie J. (1987) Chanel, Rizzoli International. Publications Inc., 108 p.

Perna R. (1987) Fashion forecasting . London, 256 p.

Polhemus T., Procter L. ( 1978) Fashion and Anti-fashion and Anthropology of Clothing and Adornment. London. $178 \mathrm{p}$.

Reich L.( 2004) Questions of Fashion, Boston, 151 p. 